\title{
Synthesis, Characterization, Theoretical and Electrochemical Studies of Pyrazoline Derivatives
}

\author{
Yahya Ben Soumane 1,2,* , Abdesselam Baouid ${ }^{1}$, El Mestafa El Hadrami ${ }^{2}$, Abdeslam Ben-Tama ${ }^{2}$, \\ Mohamed Maatallah ${ }^{1}$, Mohamed Saadi ${ }^{3}$, Lahcen EL Ammari ${ }^{3}$, Rachid Idouhli ${ }^{4}$ and Moha Berraho ${ }^{5}$ \\ ${ }^{1}$ Laboratory of Molecular Chemistry, Department of Chemistry, Faculty of Sciences Semlalia, University of \\ Cadi Ayyad, BP. 2390, 40001 Marrakech, Morocco \\ ${ }^{2}$ Laboratoire de Chimie Organique Appliquée, Faculté des Sciences et Techniques, BP 2202, Université Sidi \\ Mohamed Ben Abdellah, Fès, Morocco \\ ${ }^{3}$ Laboratoire de Chimie Appliquée des Matériaux, Centres des Sciences des Matériaux, Faculty of Sciences, \\ Mohammed V University in Rabat, Avenue Ibn Battouta, BP 1014, Rabat, Morocco \\ ${ }^{4}$ Physical-Chemistry of Materials and Environment Laboratory, Faculty of Sciences Semlalia, Cadi Ayyad \\ University, Marrakech, Morocco \\ ${ }^{5}$ Laboratoire de Chimie des Substances Naturelles, "Unité Associé au CNRST (URAC16)", Faculté des Sciences \\ Semlalia, BP 2390, Bd My Abdellah, Université Cadi Ayyad, 40000, Marrakech, Morocco
}

\begin{abstract}
The reaction of 1,3-dipolar cycloaddition of trans-anethole and three different diarylnitrilimines bearing different substituents $\mathrm{X}=\left\{\mathrm{H}, \mathrm{CH}_{3}, \mathrm{Cl}\right\}$ yield to the creation of three 1,3,4,5-tetrasubstituted pyrazoles. These reactions produce a single regioisomer. These compounds' structures were studied using diverse spectroscopic techniques such as ${ }^{1} \mathrm{H},{ }^{13} \mathrm{C}$ NMR, and HRMS. Afterwards, X-ray diffraction is performed at 5-(4-methoxyphenyl)4-methyl-1,3-diphenyl-4,5-dihydro-1H-pyrazole. Also, Density Functional Theory (DFT) is performed to characterize these cycloadducts.
\end{abstract}

Moreover, these synthesized compounds' molecular geometry and electronic structures have been studied using high-level ab initio calculations and DFT using the B3LYP functional. All geometries have been optimized at the B3LYP/6-311+G(d,p) basis set with different kinds of solvents. In the end, the protection against corrosion of copper surface is tested using these pyrazolines. As a result, the experimental analysis proved that the obtained cycloadducts belong to the pyrazoline family. Also, X-ray diffraction determined the stereochemistry of these compounds. DFT-based calculations revealed the existence of three stable conformations of each compound. The theoretical study and the experimental spectroscopic data showed perfect matching. The electrochemical investigation indicates that these pyrazoline compounds exhibit a good inhibition performance, preventing the degradation of copper in $\mathrm{NaCl}(3 \%)$ solution with a high inhibition efficiency of $80 \%$.

Keywords: Trans anethole; Stereospecific; DFT study; B3LYP; Corrosion protection; Inhibition.

\section{Introduction}

Corrosion is a significant concern in many industries, such as oil and gas refineries, renewable energies, and other industries. The corrosion cost lies approximately between 3 to $4 \%$ of the GDP of the industrial countries ${ }^{1}$. For instance, the total annual cost of corrosion in the oil and gas industries is estimated to be $\$ 1.372$ billion in 2018 by NACE International. Corrosion cost was around $\$ 3.7$ billion for petroleum refining and about $\$ 1.7$ billion for chemical and petrochemical industries ${ }^{2-4}$. In 2018, wind energy accounted for $63 \%$ of Europe's renewable energy investments, mostly offshore wind farms, which exposes these platforms and their submersible parts such as anchors, moorings, and power cables to copper corrosion ${ }^{5}$. Corrosion deteriorates structures; it imposes much safety and environmental challenges that cause risk to human life ${ }^{2}$. Therefore, implementing corrosion control and management strategies is the key to make huge savings and prevent and mitigate risks on human life. Many research teams focused on corrosion inhibition as a primary procedure to counter this optic problem. Inhibitors can be divided into three categories that are surfactant inhibitors, organic inhibitors, and inorganic inhibitors ${ }^{6}$ 
However, most of the existing corrosion inhibitors are toxic compounds that should be replaced with environment-friendly compounds.

Several studies have recently focused on using natural compounds to produce low-cost non-toxic, ecofriendly inhibitors, which decrease the risk of environmental pollution ${ }^{7}$. Nevertheless, green corrosion inhibitors provide low corrosion inhibition efficiency $^{7}$. Recently, new studies succeeded in increasing the inhibition efficiency of green compounds. For instance, Gharda et al. used linseed oil-based compounds as an eco-friendly corrosion inhibitor ${ }^{8}$. Ben Seddik et al. used raw clay (Rhassoul) as a source of inhibitor ${ }^{9}$. Similarly, pyrazole derivatives have attracted a lot of attention to metallic corrosion inhibition due to their attractive properties. These compounds' choice is based on their molecular structure considerations, i.e., the number of active centers and types of substituents present in these compounds ${ }^{10}$.

Pyrazolines' derivatives are an important class of heterocyclic compounds characterized by a fivemembered ring structure composed of three carbon atoms and two nitrogen atoms in adjacent positions. These derivatives have attracted a lot of attention because of their anticancer ${ }^{11}$, antimicrobial ${ }^{12}$, antiinflammatory ${ }^{13}$, anti-convulsant ${ }^{14}$, and anti-diabetic activities ${ }^{15}$. Therefore, the synthesis of pyrazolines has gained many researchers interested because of their non-toxicity, thermal stability, and difficult degradability ${ }^{16,17}$, which makes it an important ecofriendly corrosion inhibitor ${ }^{16}$. Many studies were performed using pyrazoline derivatives as a corrosion inhibitor to protect the metals and alloys such as steel and copper in aggressive media ${ }^{18-21}$. As copper is widely used in many urban and industrial applications such as pipelines for water supply in industrial and domestic utilities, heat conductors, and electricity transmission lines, including offshore power cables submersed in seawater ${ }^{20,22}$. It is relevant to recall that seawater is characterized by 1 to $4 \%$ of $\mathrm{NaCl}^{22}$. The presence of the chloride ions in these solutions leads to the corrosion of copper. However, the corrosion inhibition effect on copper of the pyrazolines that we have synthesized has not been reported yet.

The 1,3-dipolar cycloaddition reactions of nitrilimines on natural products such as trans-anethole give new pyrazoline derivatives due to the transanethole's double bond $\alpha$-aromatic that is involved in its reactivity ${ }^{23}$. Trans anethole responsible for the smell of the anise essential oil is extracted from two major aromatic plants: 1) the Pimpinella Anisum or Anis green and 2) Chinese star anise or star anise 24,25. Essential oils containing trans-anethole are mainly exploited in pharmacology for their antioxidant ${ }^{26,27}$, antithrombotic 28,29, gastroprotective 30,31, antimicrobial effects, and the ability to heal wounds ${ }^{32,33}$.

For all the reasons stated earlier, this work aims to 1) synthesize heterocyclic pyrazole products based on anise seeds' trans-anethole via 1,3-dipolar cycloaddition reactions, and 2) exploit these pyrazole products as green inhibitors of the corrosion of copper in seawater-like conditions

In this paper, we report the 1,3-dipolar cycloaddition of nitrilimines with trans-anethole. The variation of dipoles is used to evaluate their effect on the yield of the cycloaddition product and the reaction's regioselectivity.

DFT calculations were carried out using the B3LYP method and the $6-311+\mathrm{G}(\mathrm{d}, \mathrm{p})$ basis set to obtain, in the first place, the ground state optimized geometry of the different compounds as well as their electronic properties. Then, a comparison between theoretical predictions and collected experimental data is performed and revealed excellent matching. Finally, an electrochemical study using pyrazolines as a corrosion inhibitor for copper in $3 \% \mathrm{NaCl}$ is conducted to reproduce the seawater conditions. The electrochemical results showed that inhibition efficiency is considerably enhanced. The obtained 5(4-methoxyphenyl)-4-methyl-1,3-diphenyl-4,5-

dihydro-1H-pyrazole presents an exceptionally highefficiency green inhibitor as opposed to other green inhibitor reported in the literature as well as other produced pyrazoles in this paper ${ }^{7}$. Such a product might be an essential eco-friendly inhibitor that could be used in the coating of copper in seawater conditions in applications such as offshore power cables and marine electronic devices.

\section{Experimental}

\subsection{Materials and methods}

Melting points were measured in an open capillary tube on a Buchi 510 apparatus with no correction. Spectra were recorded on Brucker spectrometer using the ${ }^{1} \mathrm{H}$ NMR $(300 \mathrm{MHz})$ and ${ }^{13} \mathrm{C}$ NMR $(75 \mathrm{MHz})$ techniques providing chemical shift values in part per million $(\delta \mathrm{ppm})$ relative to TMS $(0.00 \mathrm{ppm})$. HighResolution Mass Spectral (HRMS) data is obtained on a Triple TOF 5600 LC/MS/MS System (AB SCIEX). The ionization mode used in mass spectra was Ion Spray Voltage (ISVF): 5500. Column Chromatography (CC) was carried out using E-Merck silica gel 60F254. The reaction progress was monitored by Thin Layer Chromatography (TLC) using silica gel 60-F254, and the spots were detected with UV light (254 or $365 \mathrm{~nm})$. Analytical and spectroscopic methods determined the structure of all the compounds compared with the structure related to the compounds reported in the literature. Reagents and solvents were purified according to the standards. Electrochemical studies were realized using a potentiostat PGZ100 equipped with a standard threeelectrode configuration: Copper as a working electrode $\left(1 \mathrm{~cm}^{2}\right)$, a platinum mesh auxiliary electrode, and a silver/silver chloride $(\mathrm{Ag} / \mathrm{AgCl}$ saturated $\mathrm{KCl})$ reference electrode. Polarization curves were carried out in a $3 \%$ sodium chloride solution as a supporting electrolyte. The specimens' immersion precedes the 
electrochemical testing in the solution for $30 \mathrm{~min}$ to stabilize the open circuit potential (OCP). The potentiodynamic polarization curves were obtained after the OCP stabilization with a scan rate of $1 \mathrm{mV} / \mathrm{s}$ from $-800 \mathrm{mV}$ to $100 \mathrm{mV}$ vs. $\mathrm{Ag} / \mathrm{AgCl}$.

\subsection{Chemistry}

The 1,2-pyrazolines derivatives $\mathbf{3}$ were synthesized by the method described in scheme 1 . To the equimolar solution $(1.28 \mathrm{mmol})$ of trans-anethole $\mathbf{1}$ and of the corresponding N-phenylarylohydrazonic acid chloride precursor $\mathbf{2}$ in a solvent (dichloromethane, chloroform, or benzene) $(15 \mathrm{~mL})$, the triethylamine $(1.35 \mathrm{mmol})$ is added dropwise. The reaction mixture was stirred at room temperature for 12 hours, and TLC monitored the progress of the reaction. After completion of the reaction, the solvents were evaporated under reduced pressure. The organic layer was dried using anhydrous sodium sulfate, then filtered and concentrated under reduced pressure to obtain the crude products. The obtained crude products were purified by silica gel CC using hexane/ethyl acetate $(9: 1 \mathrm{v} / \mathrm{v})$ to isolate the pyrazoline (Scheme 1).

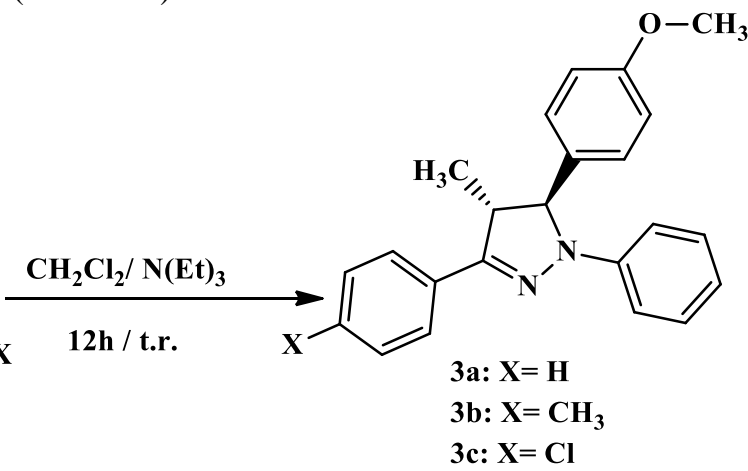

Scheme 1. Synthesis of 1,2-pyrazoline derivatives 3

\subsection{Characterization of compounds}

Compound 3a: 5-(4-Methoxyphenyl)-4-methyl-1,3diphenyl-4,5-dihydro-1H-pyrazole

Green solid. mp: $97-99^{\circ} \mathrm{C}$ (ethanol). Yield: $57 \%$.

NMR $\quad{ }^{1} \mathrm{H} \quad\left(300 \quad \mathrm{MHz}, \mathrm{CDCl}_{3}\right) \quad \delta \quad$ ppm: $1.48\left(\mathrm{~d}, \mathrm{~J}=7.2 \mathrm{~Hz}, 3 \mathrm{H}, \mathrm{CH}_{3}-\mathrm{C}-4\right), 3.49(\mathrm{~m}, 1 \mathrm{H}$, H-C-4), 3.80 (s, 3H, O-CH ${ }_{3}$, 4.86 (d, J = 4.5 Hz, 1H, H-C-5), 6.78-7.83 (m, 14H, Ar-H).

$\mathrm{NMR}{ }^{13} \mathrm{C}\left(\mathrm{CDCl}_{3}, 75 \mathrm{MHz}\right) \delta \mathrm{ppm}: 19.75\left(\mathrm{CH}_{3}-\mathrm{C}-4\right)$. 51.14 (HC-4), $55.67\left(\mathrm{O}^{-} \mathrm{CH}_{3}\right), 72.39$ (HC-5), 113.57, $114.89,119.24,126.47,126.54,127.18,128.68$, $128.75,128.80,129.02,129.35,132.61,134.01$, 144.85, $151.42(\mathrm{C}=, \mathrm{HC}=), 159.47(\mathrm{C}=\mathrm{N})$.

HRMS of $[\mathrm{M}+\mathrm{H}]^{+} \mathrm{m} / \mathrm{z}$ 343.1805, calcd for $\mathrm{C}_{23} \mathrm{H}_{23} \mathrm{ON}_{2}, 343.1766$.

Compound 3b: 5-(4-Methoxyphenyl)-4-methyl-1phenyl-3-p-tolyl-4,5-dihydro-1H-pyrazole

Green solid. mp: $155-156^{\circ} \mathrm{C}$ (ethanol). Yield: $58 \%$.

NMR ${ }^{1} \mathrm{H}\left(300 \mathrm{MHz}, \mathrm{CDCl}_{3}\right) \delta$ ppm: $1.45(\mathrm{~d}, \mathrm{~J}=7.2$ $\left.\mathrm{Hz}, 3 \mathrm{H}, \mathrm{CH}_{3}-\mathrm{C}-4\right), 2.40$ (s, 3H, $\mathrm{CH}_{3}-\mathrm{Ar}$ ), 3.42 (m, $1 \mathrm{H}$, $\mathrm{H}-\mathrm{C}-4), 3.79$ (s, 3H, O-CH $\left.{ }_{3}\right), 4.82$ (d, J = 4.5 Hz, 1H, H-C-5), 6.64-7.68 (m, 13H, Ar-H).

$\mathrm{NMR}{ }^{13} \mathrm{C}\left(\mathrm{CDCl}_{3}, 75 \mathrm{MHz}\right) \delta \mathrm{ppm}: 19.76\left(\mathrm{CH}_{3}-\mathrm{C}-4\right)$, $21.76\left(\mathrm{CH}_{3}-\mathrm{Ar}\right), 51.22$ (H-C-4), $55.65\left(\mathrm{O}-\mathrm{CH}_{3}\right), 72.30$ (H-C-5), 113.47, 114.84, 119.03, 126.44, 127.18, $129.31,129.71,129.77,134.13,138.80,144.97$, $151.61(\mathrm{C}=, \mathrm{HC}=), 159.42(\mathrm{C}=\mathrm{N})$.

HRMS of $[\mathrm{M}+\mathrm{H}]^{+} \mathrm{m} / \mathrm{z}$ 357.1961, calcd for $\mathrm{C}_{24} \mathrm{H}_{25} \mathrm{ON}_{2}, 357.1922$.
Compound 3c: 3-(4-Chlorophenyl)-5-(4methoxyphenyl)-4-methyl-1-phenyl-4,5-dihydro-1Hpyrazole

Green solid. mp: $158-160^{\circ} \mathrm{C}$ (ethanol). Yield: $61 \%$.

NMR $\quad{ }^{1} \mathrm{H} \quad\left(300 \quad \mathrm{MHz}, \quad \mathrm{CDCl}_{3}\right) \quad \delta \quad$ ppm: $1.42\left(\mathrm{~d}, \mathrm{~J}=6.9 \mathrm{~Hz}, 3 \mathrm{H}, \mathrm{CH}_{3}-\mathrm{C}_{-4}\right), 3.41(\mathrm{~m}, 1 \mathrm{H}$, $\mathrm{H}-\mathrm{C}-4), 3.77$ (s, 3H, O-CH $\left.{ }_{3}\right), 4.81$ (d, J = 4.2 Hz, 1H, H-C-5), 6.72-7.60 (m, 13H, Ar-H).

$\mathrm{NMR}{ }^{13} \mathrm{C}\left(\mathrm{CDCl}_{3}, 75 \mathrm{MHz}\right) \delta \mathrm{ppm}: 14.60\left(\mathrm{CH}_{3}-\mathrm{C}-4\right)$, 45.93 (H-C-4), $50.61\left(\mathrm{O}-\mathrm{CH}_{3}\right), 67.42$ (H-C-5), $108.55,109.87,114.42,122.07,122.54,124.16$, $124.33,126.09,128.68,129.33,139.53,145.19(\mathrm{C}=$, $\mathrm{HC}=), 154.47)(\mathrm{C}=\mathrm{N})$.

HRMS of $[\mathrm{M}+\mathrm{H}]^{+} \mathrm{m} / \mathrm{z} 377.1415$, calcd for $\mathrm{C}_{23} \mathrm{H}_{22}$ $\mathrm{ON}_{2} \mathrm{Cl}, 377.1376$.

\subsection{X-ray crystallographic data}

The compound's crystallographic data and structure refinement parameters are summarized in Table 1. The title compound's structural examinations were performed using the Bruker's 2016 APEX III diffractometer equipped with $\mathrm{Cu}$-Karadiation $(\lambda=1.5418 \AA)$ at $296 \mathrm{~K}^{34}$. The structure was solved by direct methods and successive Fourier difference synthesis using SHELXS-2014 ${ }^{35}$, then refined by full-matrix least-squares procedure on $\mathrm{F}_{2}$ with anisotropic thermal parameters ${ }^{35}$. The positions of non-hydrogen atoms were refined isotropically by SHELXL-2014 ${ }^{36}$. Hydrogen atoms were placed in chemically allowed positions. The Thermal Ellipsoid Plot (TEP) of the compound was generated using the 
ORTEP3 software package; the packing diagram was generated using Mercury software ${ }^{37,38}$. A total of 238 parameters were refined with 3912 unique reflections, which covered the residuals to R1 0.054 . Crystallographic data have been deposited to the Cambridge Crystallographic Data Centre as supplementary publication (number CCDC 1910280 for PDMF).

Copies of the data can be obtained free of charge via http://www.ccdc.cam.ac.uk/conts/retrieving.html, or from the Cambridge Crystallographic Data Centre, 12 Union Road, Cambridge CB2 1EZ, UK; fax:+44 (0)1223 336033or e-mail: deposit@ccdc.cam.ac.uk.

Table 1. Crystallographic and structure refinement parameters of the title compound $\mathbf{3 a}$.

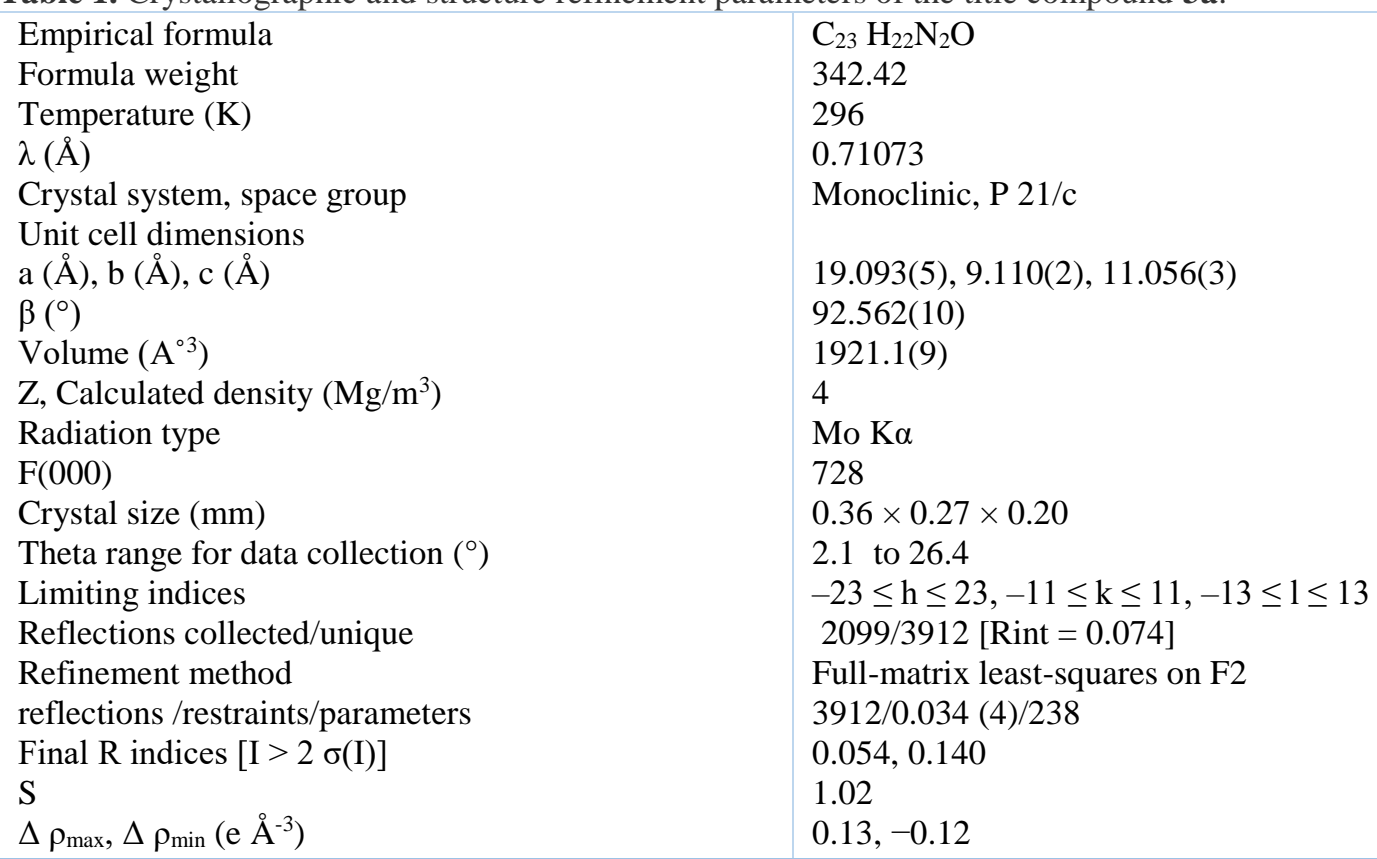

\subsection{Computational studies}

The ground state optimization was carried out using DFT with Becke-3-Lee-Yang-Parr (B3LYP) exchange-correlation functional at $6-31 \mathrm{G}(\mathrm{d}, \mathrm{p})$ and $6-311+\mathrm{G}(\mathrm{d}, \mathrm{p})$ basis set ${ }^{39,40}$. The largest basis set 6$311+\mathrm{G}(\mathrm{d}$, p) confirmed our theoretical results. Gaussian 09 software was used to perform full geometry optimizations ${ }^{41}$. The vibrational frequency calculations were performed at the same levels of theory. No imaginary frequencies were found for the optimized structures that correspond to local minima on the total potential energy surface (PES). The solvent (chloroform, dichloromethane, or benzene) effects have also been considered using the CPCM ${ }^{42}$ model as implemented in Gaussian 09.

\section{Results and Discussion}

\subsection{Synthesis of pyrazoline derivatives}

Table 2. Synthesis of 1,3,4,5-tetra-substituted pyrazolines 3 and their main characteristics of ${ }^{1} \mathrm{H}$ and ${ }^{13} \mathrm{C}$ NMR.

\begin{tabular}{|c|c|c|c|c|c|c|c|c|}
\hline \multirow{3}{*}{$\mathrm{X}$} & \multirow{3}{*}{ Compound } & \multicolumn{6}{|c|}{ NMR (ppm) } & \multirow{3}{*}{ Yield (\%) } \\
\hline & & \multicolumn{2}{|c|}{$\underline{\mathrm{H}}-\underline{\mathrm{C}}-4$} & \multicolumn{2}{|c|}{$\underline{\mathrm{H}}-\underline{\mathrm{C}}-5$} & \multicolumn{2}{|c|}{$\mathrm{CH}_{3}-\mathrm{C} 4$} & \\
\hline & & ${ }^{1} \mathrm{H}$ & ${ }^{13} \mathrm{C}$ & ${ }^{1} \mathrm{H}$ & ${ }^{13} \mathrm{C}$ & ${ }^{1} \mathrm{H}$ & ${ }^{13} \mathrm{C}$ & \\
\hline $\mathrm{H}$ & $\mathbf{3 a}$ & $3.49(\mathrm{~m})$ & 51.14 & $4.86(d)$ & 72.39 & $1.48(\mathrm{~d})$ & 14.75 & 57 \\
\hline $\mathrm{CH}_{3}$ & $\mathbf{3 b}$ & $3.42(\mathrm{~m})$ & 51.22 & $4.82(d)$ & 72.30 & $1.45(\mathrm{~d})$ & 19.75 & 58 \\
\hline $\mathrm{Cl}$ & $3 c$ & $3.41(\mathrm{~m})$ & 51.22 & $4.81(d)$ & 67.42 & $1.42(\mathrm{~d})$ & 19.60 & 61 \\
\hline
\end{tabular}

The condensation of trans-anethole 1 with the in-situ generated N-phenylarylohydrazonic acid chloride $\mathbf{2}$ from their precursors diarylnitrilimines under the action of trimethylamine, gives after stirring for 12 hours at room temperature, in dichloromethane, only varieties were purified by $\mathrm{CC}$ and isolated with average yields (57-61\%, Table 2). The structures of the obtained products 3a-c were established from the ${ }^{1} \mathrm{H}$ NMR, ${ }^{13} \mathrm{C}$ NMR, and MS. The ${ }^{1} \mathrm{H}$ and ${ }^{13} \mathrm{C}$ NMR spectra of the compounds 3a-c have a multiplet between 3.41 and $3.49 \mathrm{ppm}$ relative to the proton attached to the carbon 4 and a doublet between 4.81 and $4.86 \mathrm{ppm}$ of the hydrogen carried by the carbon 5 of the pyrazole ring. As for the carbon atoms $\mathrm{C} 4$ and $\mathrm{C} 5$ of the pyrazoline ring, the first resonates between 51.14 and $51.22 \mathrm{ppm}$ while the second resonates between 67.42 and $72.39 \mathrm{ppm}$. one regioisomer 3a-c (Scheme 1). The products 3a-c 


\subsection{Single crystal $X$-ray structural analysis of the} title compound

As the compound $\mathbf{3 b}$ is not a crystal, no X-ray

structural analysis has been performed on it. Moreover, the X-ray structural analysis of compound $3 \mathbf{c}$ has been carried out before ${ }^{23}$. In the end, the crystalline analysis study in this paper focused only on the product $\mathbf{3 a}$ to confirm its stereochemistry structures.

The structure and geometry of the title compound $\mathbf{3 a}$ in the solid-state are established by single-crystal $\mathrm{X}$-ray structural analysis. This compound crystallizes in the monoclinic system with $\mathrm{P} 2{ }_{1} / \mathrm{C}$ space group and one molecule in the asymmetric unit. The title compound's molecular structure is illustrated in
Figure 1, and the packing diagram is depicted in Figure 2. Crystal data collection and structure refinement details are summarized in Table 1 . The pyrazole system is almost perpendicular to methoxyphenyl group with a dihedral angle of $88.27(9)\left({ }^{\circ}\right)$ whereas the dihedral angles between the two attached phenyl are 22.02(10) $\left(^{\circ}\right)$ and $10.62(11)\left({ }^{\circ}\right)$ respectively. There is an intramolecular $\mathrm{C}-\mathrm{H} \cdots \mathrm{N}$ hydrogen bond involving a nitrogen atom $\mathrm{N} 2$, and the $\mathrm{H}$ atom of the $\mathrm{C} 17$ of the phenyl group forming an $\mathrm{S}(5)$ ring motif. In the crystal, molecules are linked by pairs of $\mathrm{C}-\mathrm{H} \cdots \pi$ interactions, forming inversion dimers (Table 3 and Figure 3). There are no other significant intermolecular interactions.

Table 3. Hydrogen-bond geometry $\left(\AA{ }^{\circ}\right)$. Cg is the centroid of the $\mathrm{C} 10 / \mathrm{C} 11-\mathrm{C} 15$ ring.

\begin{tabular}{|c|c|c|c|c|}
\hline$D-\mathrm{H} \cdots A$ & $D-\mathrm{H}$ & $\mathrm{H} \cdots A$ & $D \cdots A$ & $D-\mathrm{H} \cdots A$ \\
\hline $\mathrm{C} 17-\mathrm{H} 17 \cdots \mathrm{N} 2$ & 0.93 & 2.47 & $2.784(3)$ & 100 \\
\hline $\mathrm{C} 23-\mathrm{H} 23 B \cdots C g 3^{\mathrm{i}}$ & 0.96 & 2.86 & $3.765(2)$ & 158 \\
\hline Symmetry code & & (i) $\mathrm{x},-\mathrm{y}+1 / 2, \mathrm{z}-3 / 2$.
\end{tabular}

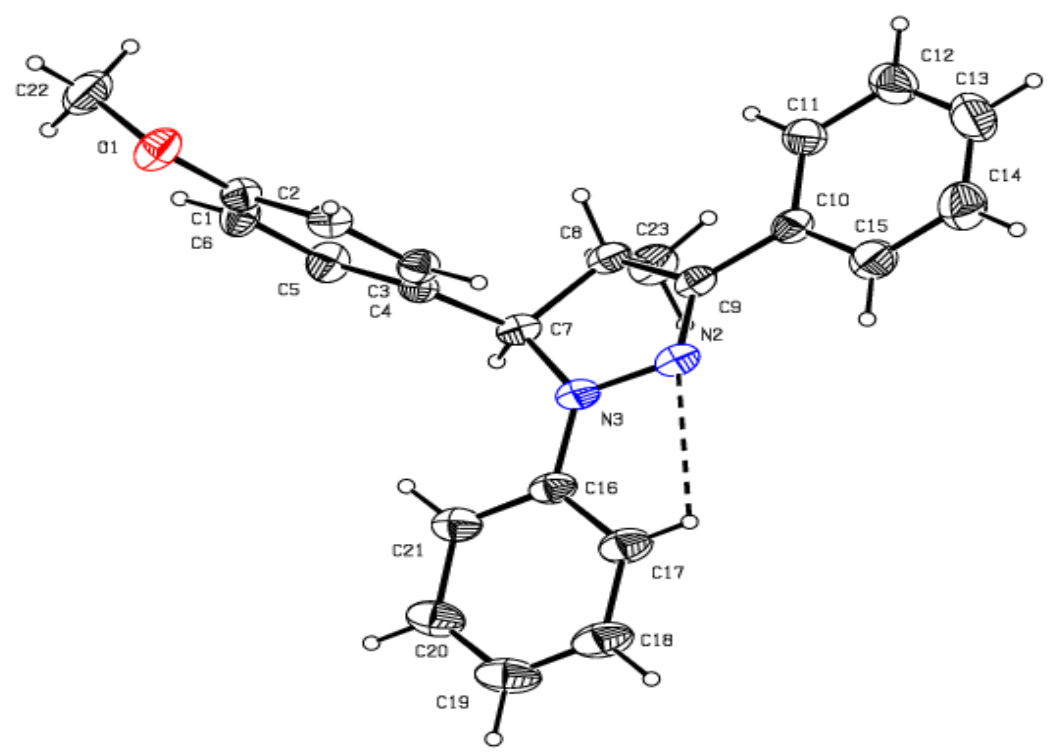

Figure 1. The TEP of the 5-(4-methoxyphenyl)-4-methyl-1,3-diphenyl-4,5-dihydro-1H-pyrazole 3a

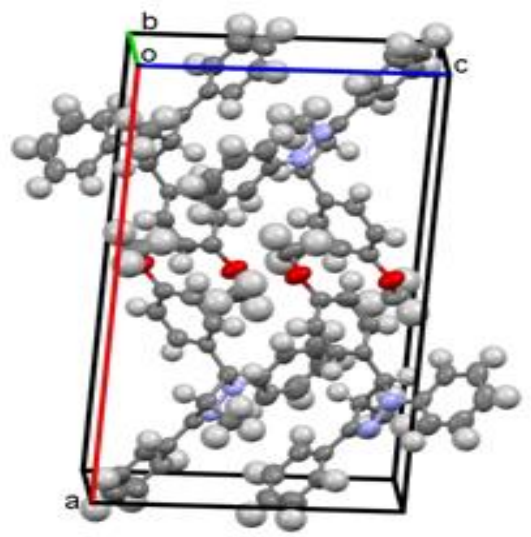

Figure 2. A view of the packing diagram of the crystal title $\mathbf{3 a}$ 


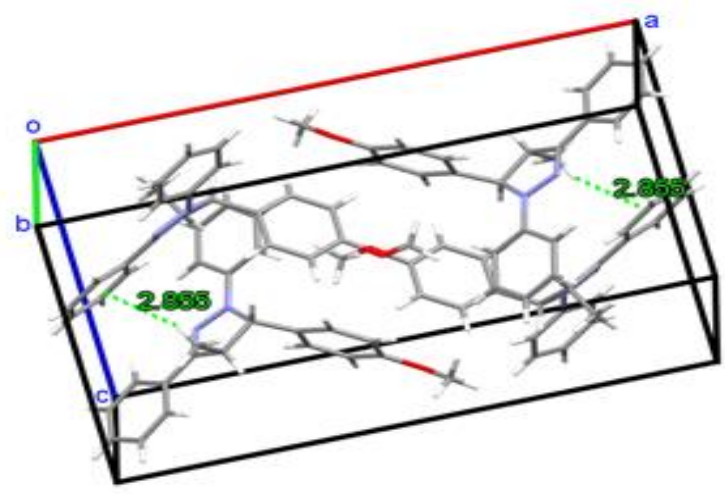

Figure 3. A partial view of the packing diagram of the crystal title $\mathbf{3 a}$

\subsection{DFT computation and electronic structure}

\subsubsection{Geometry optimization}

The structures of all possible isomers from the reaction 1,3-dipolar cycloaddition of trans-anethole $\mathbf{1}$ and diarylnitrilimines was studied theoretically to explore the total PES and find the lowest energy conformers. Structures were fully optimized first at the B3LYP/6-31G(d, p) level. Then they were optimized at the high B3LYP/6-311+G(d, p) level of theory, confirming our theoretical study. In order to evaluate the existence or absence of a solvent effect on this reaction, calculations were carried out in gas phase and with different types of solvent. For each compound, three conformers on the total PES were localized and optimized. The absence of imaginary wave number values after calculating the harmonic vibrational frequencies confirms that all of the optimized conformations correspond to equilibrium minima on the total PES. The optimized geometries and relative energies of the obtained structures are shown in Figure 4 and Table 4 respectively.

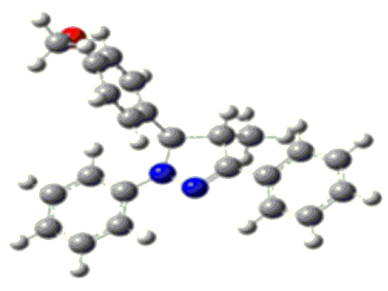

3a1

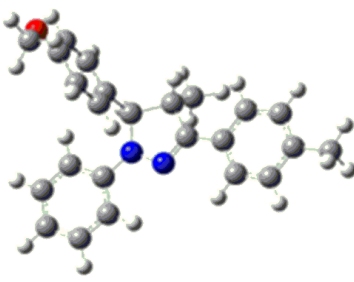

$3 b 1$

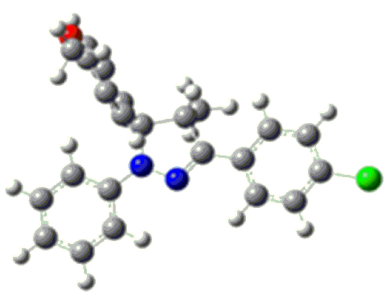

$3 \mathrm{c} 1$

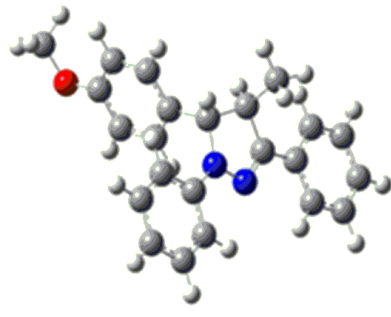

$3 \mathbf{a 2}$

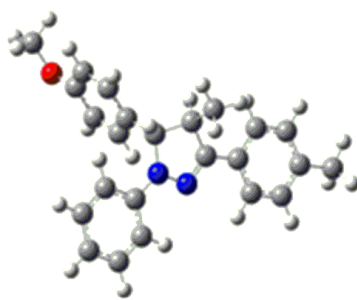

$3 b 2$

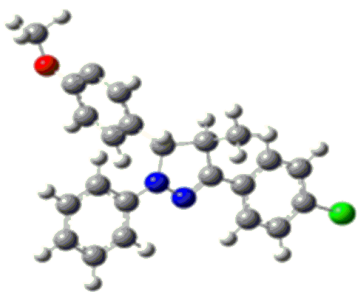

$3 \mathbf{c 2}$

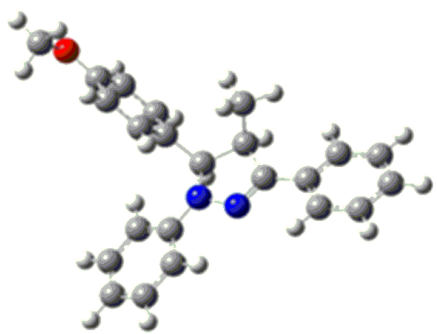

$3 a 3$

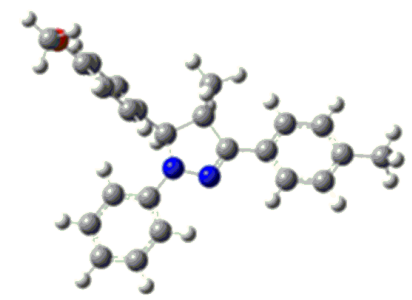

$3 \mathrm{~b} 3$

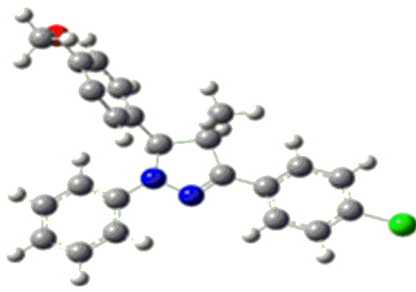

$3 \mathrm{c} 3$

Figure 4. Optimized structure of the condensation of trans-anethole and diarylnitrilimines at B3LYP/6-311+G(d, p) level in the gas phase 
Table 4. Relative energies $(\mathrm{kJ} / \mathrm{mol})$ of the studied structures with various substituents $\left(\mathrm{R}=\mathrm{H}, \mathrm{CH}_{3}\right.$, and $\left.\mathrm{Cl}\right)$ at B3LYP/6-31G(d,p) and B3LYP/6-311+G(d,p) levels of theory.

\begin{tabular}{|c|c|c|c|}
\hline \multirow{2}{*}{ Compound } & \multirow{2}{*}{ Isomers } & \multicolumn{2}{|c|}{$\Delta \mathrm{E}(\mathrm{KJ} / \mathrm{mol})$} \\
\cline { 3 - 4 } & & B3LYP/6-31G(d,p) & B3LYP/6-311+G(d,p) \\
\hline \multirow{3}{*}{$\mathrm{R}=\mathrm{H}$} & $3 \mathrm{c} 1$ & 0.00 & 0.00 \\
\hline & $3 \mathrm{c} 2$ & 0.64 & 0.76 \\
\hline \multirow{2}{*}{$\mathrm{R}=\mathrm{CH}_{3}$} & $3 \mathrm{c} 3$ & 8.4 & 9.65 \\
\hline & $3 \mathrm{~b} 1$ & 0.00 & 0.00 \\
\hline \multirow{2}{*}{$\mathrm{R}=\mathrm{Cl}$} & $3 \mathrm{~b} 2$ & 0.48 & 0.60 \\
\hline & $3 \mathrm{~b} 3$ & 8.10 & 9.33 \\
\hline & $3 \mathrm{a} 1$ & 0.00 & 0.00 \\
\hline & $3 \mathrm{a} 2$ & 0.50 & 0.67 \\
\hline
\end{tabular}

The results reported in Table 4 showed that the energy differences between the different isomers are extremely weak. Moreover, the structural arrangement is preserved when the radical $\mathrm{H}$ is substituted with $\mathrm{CH}_{3}$ or $\mathrm{Cl}$ alongside the global energy minimum of the isomers $\mathbf{3 a 1}, \mathbf{3 b} \mathbf{1}$, and $\mathbf{3 c 1}$. Furthermore, the trans-structure is always favored by the experimental results, although the energy difference is still meager (above $9 \mathrm{~kJ} / \mathrm{mol}$ ). The solvent effect on the isomers 3a product is examined, and no effect is observed. The structural arrangement is kept the same for the absolute minimum of $\mathbf{3 a 1}$, as described in Table 5. As a result, the structure of the global energy minimum of (3a) is comparable to that determined experimentally.

Table 5. Relative energies (kJ/mol) of 5-(4-methoxyphenyl)-4-methyl-1,3-diphenyl-4,5-dihydro-1H-pyrazole 3a isomers in different solvents calculated at B3LYP/6-311+G(d,p) level of theory.

\begin{tabular}{|c|c|c|c|}
\hline & & \multicolumn{3}{|c|}{$\Delta \mathrm{E}(\mathrm{KJ} / \mathrm{mol})$} & $\underline{\mathbf{3}} \mathbf{3}$ \\
\hline & $\underline{\mathbf{3}} \mathbf{1}$ & $\underline{\mathbf{3}} \mathbf{2}$ & 9.66 \\
\hline Gaz Phase & 0.00 & 4.8 & 9.83 \\
\hline $\mathrm{CH}_{2} \mathrm{Cl}_{2}$ & 0.00 & 4.8 & 9.83 \\
\hline $\mathrm{CHCl}_{3}$ & 0.00 & 4.8 & 9.71 \\
\hline $\mathrm{C}_{6} \mathrm{H}_{6}$ & 0.00 & 4.8 & \\
\hline
\end{tabular}

The bond distances and angles of both optimized calculations and experiments are listed in Table 6 and 7. The agreement of both calculated and experimental results is revealed. These geometrical parameters are designated according to the orientation showed in Figure 1.

\subsubsection{HOMO-LUMO analysis}

The molecule's chemical stability is estimated from the energy gap between the highest occupied molecular orbital (HOMO) and the lowest unoccupied molecular orbital (LUMO). These orbital energies HOMO and LUMO reflect the electron donation and electron-accepting ability of the molecules, respectively. Furthermore, the energy band gap is another reactivity parameter, which can be used to predict the chemical reactivity and adsorption tendency of the inhibitor molecule. A compound with a lower energy band gap is mainly associated with high chemical reactivity and acts as an efficient corrosion inhibitor. Therefore, to have an idea of the energies and electronic distributions of our compound 3a, the highest, second highest molecular orbitals (HOMO, HOMO-1) and the lowest, second-lowest unoccupied molecular orbital (LUMO, LUMO+1) of 3a compound are depicted in Figure 5. The physicochemical properties of product $\mathbf{3} \mathbf{a}$ are reported in Table 8. In this case, the highest occupied and the lowest unoccupied molecular orbital are correctly localized on the molecular core with high electron density on nitrogen atoms and the benzene ring linked to it. The HOMO-1 and LUMO+1are localized in the region that is close to the oxygen. The HOMO energy is $-5.14 \mathrm{eV}$, and LUMO energy is $-1.48 \mathrm{eV}$, and the determined energy gap value is $3.66 \mathrm{eV}$. The physicochemical properties used in Table 8 such as the chemical hardness $(\eta)$, softness (S), electronegativity $(\chi)$, and chemical potential $(\mu)$ are defined using equations (1-4):

$\eta=(I-A) / 2$

$S=\eta / 2$ 
$\chi=(I+A) / 2$

$\mu=-(I+A) / 2$

where I and A are the ionized energy and electron affinity of the compound are given by $\left(\mathrm{I}=-\mathrm{E}_{\text {номо }}\right.$ and $\mathrm{A}=-\mathrm{E}_{\text {LUMO }}$ ).

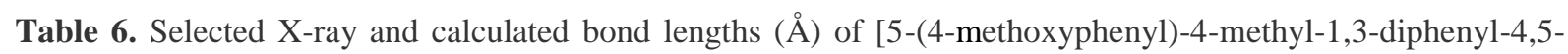
dihydro-1H-pyrazole].

\begin{tabular}{|c|c|c|}
\hline Bond lengths & X-Ray $(\AA)$ & Calc $(\mathrm{B} 3 L Y P / 6-311+\mathrm{G}(\mathrm{d}, \mathrm{p}))(\AA)$ \\
\hline $\mathrm{N} 2-\mathrm{N} 3$ & $1.370(2)$ & 1.362 \\
\hline $\mathrm{N} 3-\mathrm{C} 7$ & $1.471(2)$ & 1.475 \\
\hline $\mathrm{C} 7-\mathrm{C} 8$ & $1.538(2)$ & 1.558 \\
\hline $\mathrm{C} 8-\mathrm{C} 9$ & $1.505(2)$ & 1.523 \\
\hline $\mathrm{N} 2-\mathrm{C} 9$ & $1.298(2)$ & 1.293 \\
\hline
\end{tabular}

Table 7. Selected X-ray and calculated angles $\left(^{\circ}\right)$ of [5-(4-methoxyphenyl)-4-methyl-1,3-diphenyl-4,5-dihydro1H-pyrazole].

\begin{tabular}{|c|c|c|}
\hline Angles & X-Ray $\left({ }^{\circ}\right)$ & Cal $(\mathrm{B} 3 \mathrm{LYP} / 6-331+\mathrm{G}(\mathrm{d}, \mathrm{p}))\left({ }^{\circ}\right)$ \\
\hline $\mathrm{N} 2-\mathrm{N} 3-\mathrm{C} 7$ & $112.49(13)$ & 112.52 \\
\hline $\mathrm{N} 3-\mathrm{C} 7-\mathrm{C} 8$ & $101.83(13)$ & 101.15 \\
\hline $\mathrm{C} 7-\mathrm{C} 8-\mathrm{C} 9$ & $101.61(14)$ & 101.05 \\
\hline $\mathrm{C} 8-\mathrm{C} 9-\mathrm{N} 2$ & $113.12(16)$ & 112.43 \\
\hline $\mathrm{C} 9-\mathrm{N} 2-\mathrm{N} 3$ & $108.86(15)$ & 109.96 \\
\hline
\end{tabular}

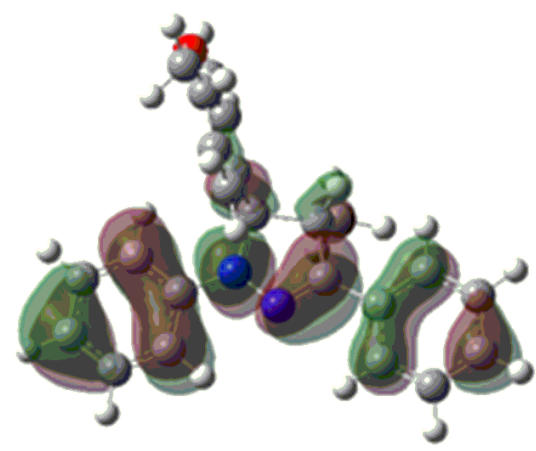

HOMO

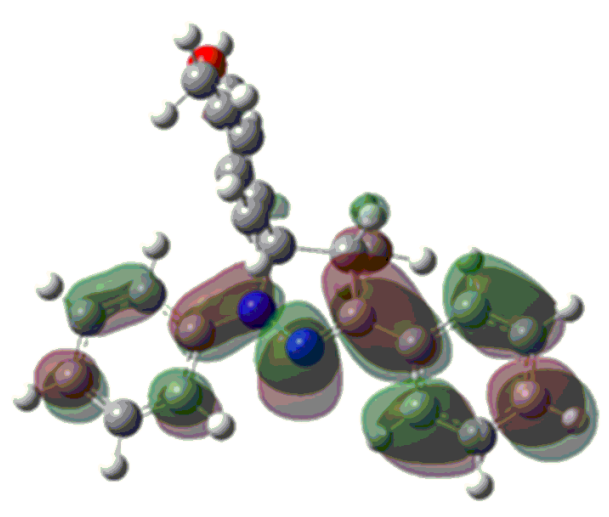

LUMO

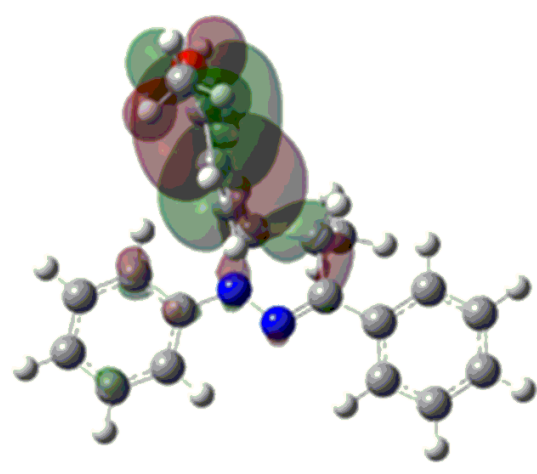

HOMO-1

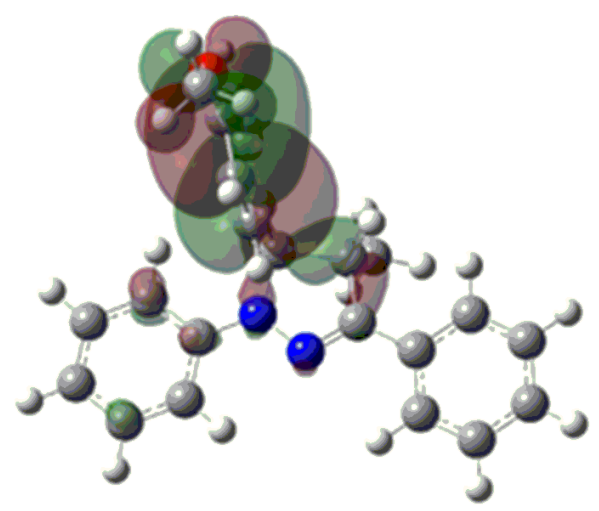

LUMO+1

Figure 5. The HOMO and LUMO molecular orbital diagram 
Table 8. The physicochemical properties of compound 3a.

\begin{tabular}{|c|c|}
\hline Parameters in $(\mathrm{eV})$ & B3LYP \\
\hline E HOMO & -5.14 \\
\hline ELUMO & -1.48 \\
\hline Ionization energy & 5.14 \\
\hline Electron affinity & 1.48 \\
\hline Gap & 3.66 \\
\hline Hardness & 1.83 \\
\hline Softness & 0.27 \\
\hline Global electronegativity & 3.31 \\
\hline Chemical potential & -3.31 \\
\hline
\end{tabular}

\subsubsection{Molecular electrostatic potential}

The depiction of molecular electrostatic potential (MEP) surfaces helps visualize relative polarity and reactive active sites of molecules. It is especially vital for estimating and identifying the reactive sites for a nucleophilic or electrophilic attack. The values of electrostatic potential are represented by different colors at the surface of the molecule. Red in the regions of most electronegative electrostatic potential, blue regions represent the most positive electrostatic potential, and green regions represent regions of zero potential.
The color code surface of our product shown in Figure 6 was determined based on the absolute minimum located on the total PES that is optimized using B3LYP/6-311+G(d,p). The electron-rich region is situated on the Penta ring, which compresses the $\mathrm{CN}$ double bond (C8-N1-N2) as indicated in our compound's MEP maps. The relative negative regions are also located on the phenyl ring because of the hydrogen bond (H-C17). This is in good agreement with the results of the crystalline studies (Figure 1). Conversely, the molecule is surrounded by relative positive regions characterized by an electrophilic reactivity, especially those with exterior hydrogen atoms.

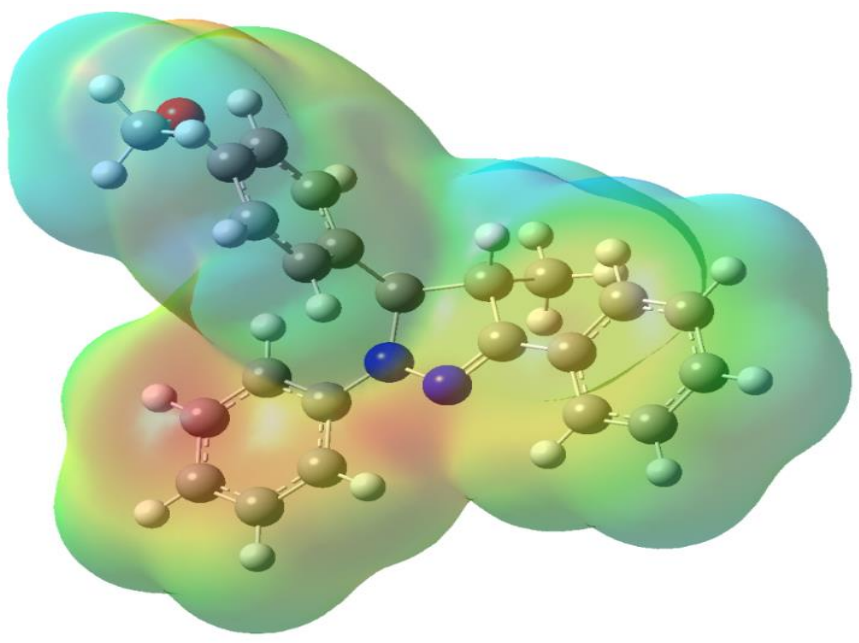

Figure 6. MEP of the compound 3a

\subsection{Electrochemical study}

Potentiodynamic Polarization Measurements curves of copper in $\mathrm{NaCl}(3.0 \%)$ solution without and with the inhibitors at $20^{\circ} \mathrm{C}$ are shown in Figure 7 . The corresponding electrochemical kinetic parameters such as corrosion potential $\left(\mathrm{E}_{\mathrm{corr}}\right)$, corrosion current density ( $i_{\text {corr }}$ ), anodic and cathodic Tafel slopes $\left(b_{a}, b_{c}\right)$, and inhibition efficiency $\eta(\%)$ are reported in Table 8 . Solution with $10^{-3} \mathrm{M}$ of inhibitors was also used to study the corrosion inhibition of copper. The inhibition efficiency was calculated using the following equation (5) ${ }^{43}$ :

$\eta(\%)=\frac{i_{\text {corr }}^{\prime}-i_{\text {corr }}}{i_{\text {corr }}^{\prime}} \times 100$

where $i_{\text {corr }}^{\prime}$ and $i_{\text {corr }}$ are the corrosion current densities with and without inhibitors, respectively. 


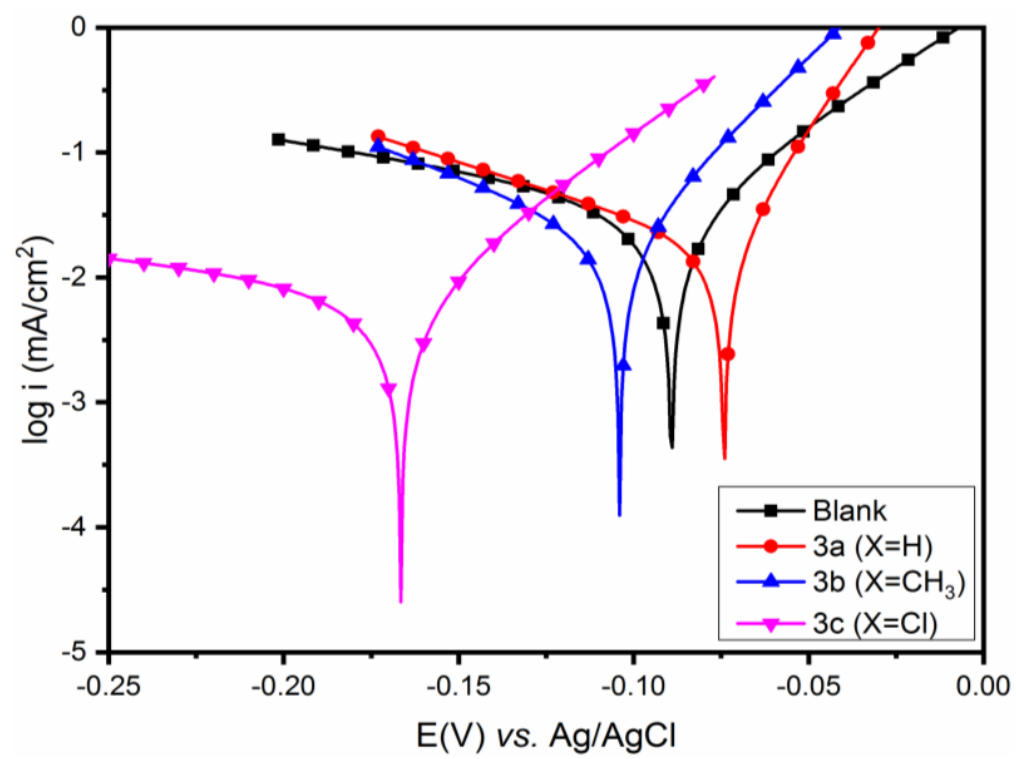

Figure 7. Potentiodynamic polarization plots for copper immersed in $3.0 \% \mathrm{NaCl}$ without and with inhibitors $\left(\mathrm{T}=20^{\circ} \mathrm{C}\right.$; concentration of inhibitors $\left.=10^{-3} \mathrm{M}\right)$

The polarization curves for copper in $3.0 \% \mathrm{NaCl}$ solution, without and with inhibitors, are shown in Figure 7. It is observed that the anodic curves of all inhibitors decreased relatively compared to the blank. On the other hand, the cathodic curves are shifted clearly with the addition of inhibitors. This result indicated that the inhibitors reduced the rate of cathodic hydrogen evolution reaction and anodic dissolution of metal ${ }^{44}$. Moreover, the corrosion potential $\left(E_{\text {corr }}\right)$ is slightly shifted than the blank $(\approx 15-77 \mathrm{mV})$, as described in Table 9. In general, an inhibitor is classified as an anodic or a cathodic type if the displacement in corrosion potential $\left(\mathrm{E}_{\text {corr }}\right)$ values against the blank is larger than $85 \mathrm{mV}^{45,46}$. In the present study, $\mathrm{E}_{\text {corr }}$ shifted within $85 \mathrm{mV}$, suggesting the mixed type inhibitor.

These variations in the copper's corrosion behavior are interpreted as the adsorption of inhibitors onto the material surface ${ }^{47}$.

Table 9. Polarization parameters for copper in $\mathrm{NaCl}$ (3.0\%) medium without and with inhibitors.

\begin{tabular}{|c|c|c|c|c|c|}
\hline $\begin{array}{c}\text { Conc. } \\
\left(10^{-3} \mathrm{~mol} / \mathrm{L}\right)\end{array}$ & $\begin{array}{c}\mathrm{E}_{\text {corr }} \\
(\mathrm{mV} v s . \mathrm{Ag} / \mathrm{AgCl}))\end{array}$ & $\begin{array}{c}\mathrm{i}_{\text {corr }} \\
\left(\mu \mathrm{A} / \mathrm{cm}^{2}\right)\end{array}$ & $\begin{array}{c}\mathrm{b}_{\mathrm{a}} \\
(\mathrm{mV} / \mathrm{dec})\end{array}$ & $\begin{array}{c}\mathrm{b}_{\mathrm{c}} \\
(\mathrm{mV} / \mathrm{dec})\end{array}$ & $\begin{array}{c}\eta \\
(\%)\end{array}$ \\
\hline Blank & -89 & 38.87 & 58 & 218 & -- \\
\hline 3a $(X=H)$ & -74 & 17.84 & 25 & 112 & 46.38 \\
\hline 3b $\left(X=C H_{3}\right)$ & -104 & 21.18 & 37 & 95 & 45.50 \\
\hline 3c $(X=C l)$ & -166 & 07.75 & 52 & 310 & $\mathbf{8 0 . 0 6}$ \\
\hline
\end{tabular}

From Table 9, it is clear that the addition of inhibitors moved the corrosion current density to lower values compared to the blank solution. In the presence of $\mathbf{3 a}$ and $\mathbf{3 b}$, the inhibition efficiency is around $46 \%$. In the presence of $\mathbf{3 c}$, the cathodic curve was characterized by limiting the diffusion current density. The presence of aromatic $\pi$-electron and heteroatoms such as $\mathrm{O}$ and $\mathrm{N}$ is common between all three compounds. The difference in inhibition efficiency is caused by the utilized radical. The experimental data showed that $80 \%$ of product $\mathbf{3} \mathbf{c}$ outperforms products $\mathbf{3} \mathbf{a}$, and $\mathbf{3 b}$.
The adsorption mechanism of these compounds on the copper surface in $3 \% \mathrm{NaCl}$ media is described in Figure 8 . The first stage of adsorption of molecules on the copper surface involves replacing water molecules primarily adsorbed on the surface, as shown in reaction (6) ${ }^{48}$. In the present case, the high electron density localized on nitrogen atoms and the benzene ring linked, as described in the theoretical parts. This observation explains that the electron's donor's ability of these compounds leads to chemical adsorption of the inhibition on the copper surface.

$\operatorname{Inh}_{(\mathrm{sol})}+\mathbf{X} . \mathrm{H}_{2} \mathbf{O}_{(\mathrm{ads})} \leftrightarrow \operatorname{Inh}_{(\mathrm{ads})}+\mathbf{X} \cdot \mathbf{H}_{2} \mathbf{O}_{(\mathrm{sol})}$ 


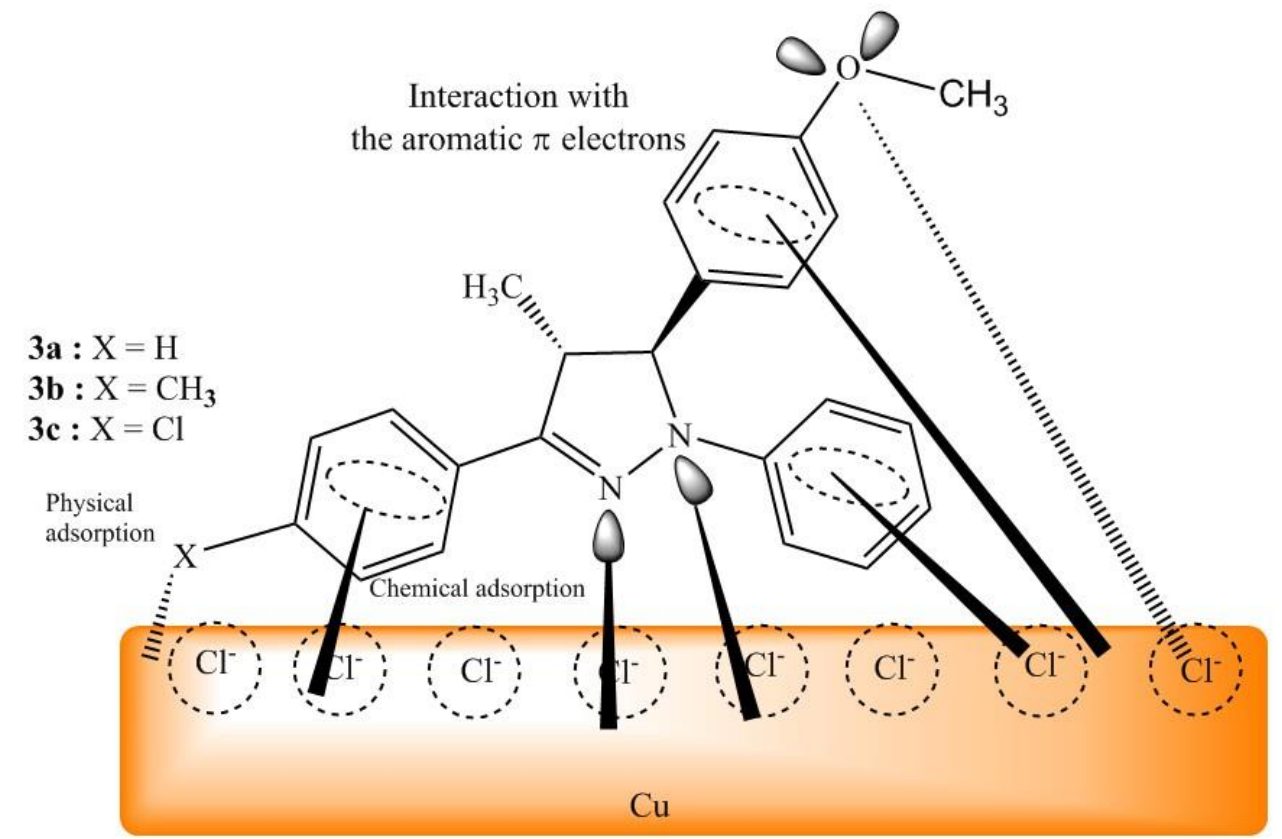

Figure 8. The inhibition mechanism of inhibitor molecules onto the copper surface in $\mathrm{NaCl}$ solution

\section{Conclusion}

The synthesis of a series of pyrazolines has been carried out successfully and efficiently under mild conditions using 1,3-dipolar cycloaddition reactions of trans-anethole and diarylnitrilimines. These reactions are regioselective and stereospecific, as identified by NMR spectroscopy and monocrystalline $\mathrm{X}$-ray analysis. The results of the theoretical calculation are in good agreement with those obtained experimentally. The corrosion behavior of copper in the presence of these synthetic compounds has been studied in a $3 \% \mathrm{NaCl}$ solution. The inhibition efficiency of the used inhibitors increases in the following order $\mathrm{X}=\mathrm{CH}_{3}<\mathrm{X}=\mathrm{H}<\mathrm{X}=\mathrm{Cl}$ to attain a higher inhibition of $80 \%$, suggesting compound $\mathrm{X}=\mathrm{Cl}$ as a corrosion inhibitor. Also, the theoretical study is in good agreement with the electrochemical study.

\section{Acknowledgments}

The authors are grateful for the "Institute of Molecular Sciences" technical support belonging to the University of Valencia, Spain. In particular, our gratitude goes to our collaborators Dr. Miguel Julve and Dr. Salah-Eddine Stiriba, for opening their labs to conduct the experimental analysis reported in this paper.

\section{References}

1- I. Bassey, Recent Advances in Computational Design of Organic Materials for Corrosion Protection of Steel in Aqueous Media, Dev Corros Prot., 2014, 125-148.

2- B. El Ibrahimi, A. Jmiai, L. Bazzi, S. El Issami, Amino acids, and their derivatives as corrosion inhibitors for metals and alloys, Arab J Chem., 2020, 13, 740-771.
3- U. Bharatiya, P. Gal, A. Agrawal, M. Shah, A. Sircar, Effect of corrosion on crude oil and natural gas pipeline with an emphasis on prevention by eco-friendly corrosion inhibitors: A comprehensive review, J Bio-and TriboCorrosion., 2019, 5, 35.

4- G. H. Koch, M. P. H. Brongers, N. G. Thompson, Y. P. Virmani, J. H. Payer, others, Corrosion cost and preventive strategies in the United States, 2002.

5- M. Kausche, F. Adam, F. Dahlhaus, J. Großmann, Floating offshore wind-Economic and ecological challenges of a TLP solution, Renew Energy, 2018, 126, 270-280.

6- L. Saqalli, M. Galai, N. Gharda, M. Sahrane, R. Ghailane, M. E. Touhami, Y. Peres-lucchese, A. Souizi, N. Habbadi, Corrosion Inhibition of Carbon Steel by Anthraquinones Derivatives in 1.0 M HCl: Electrochemical and Quantum Calculations, Int J Electrochem Sci., 2018, 13, 5096-5119.

7- A. Fateh, M. Aliofkhazraei, A. R. Rezvanian, Review of corrosive environments for copper and its corrosion inhibitors, Arab J Chem., 2020, 13, 481-544.

8- N. Gharda, M. Galai, L. Saqalli, N. Habbadi, R. Ghailane, A. Souizi, M. E. Touhami, Y. PeresLucchese, Linseed oil as a novel eco-friendly corrosion inhibitor of carbon steel in $1 \mathrm{M} \mathrm{HCl}$, Surf Rev Lett., 2019, 26, 1850148.

9- N. Ben Seddik, I. Raissouni, K. Draoui, A. A. Aghzzaf, A. Chraka, B. Aznag, F. Chaouket, D. Bouchta, Calcite, the main corrosion inhibitor contained in the raw clay (Rhassoul) of brass in $3 \% \mathrm{NaCl}$ medium, Mediterr J Chem., 2019, 9, 236-248.

10-M. Ouakki, H. Chahmout, S. Sibous, M. Galai, Z. Benzakri, S. Boukhris, A. Souizi, 
M. Cherkaoui, Novel pyrazole derivatives as inhibitors of stainless steel in $2.0 \mathrm{M} \mathrm{H}_{2} \mathrm{SO}_{4}$ media: Electrochemical Study, Mediterr J Chem., 2020, 10, 239-252.

11-F. Tok, B. Abas, Ö. Çevik, B. Kogit-

Kaymakçığlu , Design, synthesis, and biological evaluation of some new 2-Pyrazoline derivatives as potential anticancer agents, Bioorg Chem., 2020, 102, 104063.

12-M. Asad, M. N. Arshad, M. Oves, M. Khalid, S. A. Khan, A. M. Asiri, M. Rehan, H. Dzudzevic-Cancar, N-Trifluoroacetylated pyrazolines: Synthesis, characterization and antimicrobial studies, Bioorg Chem., 2020, 103842.

13-X. Cai, S. Zhao, D. Cai, J. Zheng, Z. Zhu, D. Wei, Z. Zheng, H. Zhu, Y. Chen, Synthesis and evaluation of novel D-ring substituted steroidal pyrazolines as potential antiinflammatory agents, Steroids, 2019, 146, 70-78.

14-S. Farooq, Z. Ngaini, One-pot and two-pot synthesis of chalcone based mono and bispyrazolines, Tetrahedron Lett., 2020, 61, 151416.

15-L. Kumar, K. Lal, P. Yadav, A. Kumar, A. K. Paul, Synthesis, characterization, $\$ \alpha \$-$ glucosidase inhibition and molecular modeling studies of some pyrazoline-1H-1, 2, 3-triazole hybrids, J Mol Struct., 2020, 128253.

16-P. Singh, M. Nath, A Concise Account on Ecofriendly Synthetic Strategies for Pyrazole Heterocycles, Curr Green Chem., 2019, 6, 198-209.

17-G. da Silva, Thermal decomposition of pyrazole to vinylcarbene+ N2: A first-principles/RRKM study, Chem Phys Lett., 2009, 474, 13-17.

18-H. Lgaz, R. Salghi, A. Chaouiki, S. Jodeh, K. S. Bhat, others, Pyrazoline derivatives as possible corrosion inhibitors for mild steel in acidic media: A combined experimental and theoretical approach, Cogent Eng., 2018, 5, 1441585.

19-A. Goswami, S. Koskey, T. Mukherjee, O. Chyan, Study of pyrazole as a copper corrosion inhibitor in Alkaline post chemical mechanical polishing cleaning solution, ECS J Solid State Sci Technol., 2014, 3, 293-297.

20-H. Lgaz, S. K. Saha, A. Chaouiki, K. S. Bhat, R. Salghi, Shubhalaxmi, P. Banerjee, I. H. Ali, M. I. Khan, I. M. Chung, Exploring the potential role of pyrazoline derivatives in corrosion inhibition of mild steel in hydrochloric acid solution: Insights from experimental and computational studies, Constr Build Mater., 2020, 233, 117320.

21-I. Selatnia, A. Sid, 1-Formyl-3-Phenyl-5-Aryl-2Pyrazoline Derivatives as Corrosion Inhibitors of Steel in Acidic Medium : Computational Simulations Study, J New Technol Mater., 2018, 8, 120-125.

22-K. S. Johnson, R. M. Pytkowicz, The activity of $\mathrm{NaCl}$ in seawater of $10-40 \%$ salinity and $5-25^{\circ} \mathrm{C}$ at 1 atmosphere, Mar Chem., 1981, 10, 85-91.

23-Y. Ben Soumane, A. Baouid, E. M. El Hadrami,
L. El Ammari, M. Saadi, M. Berraho, (4S, 5R)-3(4-Chlorophenyl)-5-(4-methoxyphenyl)-4methyl-1-phenyl-4, 5-dihydro-1H-pyrazole, IUCrData, 2016, 1, x161022.

24-I. Kosalec, S. Pepeljnjak, D. Kuštrak, Antifungal activity of fluid extract and essential oil from anise fruits (Pimpinella anisum L., Apiaceae), Acta Pharm., 2005, 55, 377-385.

25-A. Padmashree, N. Roopa, A. D. Semwal, G. K. Sharma, G. Agathian, A. S. Bawa, Star-anise (Illicium verum) and black caraway (Carum nigrum) as natural antioxidants, Food Chem., 2007, 104, 59-66.

26- A. F. Ahmed, M. Shi, C. Liu, W. Kang, Comparative analysis of antioxidant activities of essential oils and extracts of fennel (Foeniculum vulgare Mill.) seeds from Egypt and China, Food Sci Hum Wellness, 2019, 8, 67-72.

27-Â. Luis, S. Sousa, J. Wackerlig, D. Dobusch, A. P. Duarte, L. Pereira, F. Domingues, Star anise (Illicium verum Hook. f.) essential oil: Antioxidant properties and antibacterial activity against Acinetobacter baumannii, Flavour Fragr J., 2019, 34, 260-270.

28-A. Kwiatkowski Pawełand Pruss, H. Masiuk, M. Mnichowska-Polanowska, M. Kaczmarek, S. Giedrys-Kalemba, B. Dołlkegowska, H. Zielińska-Bliźniewska, J. Olszewski, M. Sienkiewicz, The effect of fennel essential oil and trans-anethole on antibacterial activity of mupirocin against Staphylococcus aureus isolated from asymptomatic carriers, Adv Dermatology Allergol Dermatologii i Alergol., 2019, 36, 308.

29-E. Seo, P. Kang, G. H. Seol, Trans-anethole prevents hypertension induced by chronic exposure to both restraint stress and nicotine in rats, Biomed Pharmacother., 2018, 102, 249-253.

30-M. Tanveer, C. Wagner, M. I. ul Haq, N. C. Ribeiro, T. Rathinasabapathy, M. S. Butt, A. Shehzad, S. Komarnytsky, Spicing up gastrointestinal health with dietary essential oils, Phytochem Rev., 2020, 1-21.

31-J. K. Patra, G. Das, S. Bose, S. Banerjee, C. N. Vishnuprasad, M. del Pilar Rodriguez-Torres, H.-S. Shin, Star anise (Illicium verum): Chemical compounds, antiviral properties, and clinical relevance, Phytother Res., 2020, 34, 1248-1267.

32-J. Wieczyńska, I. Cavoski, Antimicrobial, antioxidant and sensory features of eugenol, carvacrol, and trans-anethole in active packaging for organic ready-to-eat iceberg lettuce, Food Chem., 2018, 259, 251-260.

33-N. H. Kang, S. Mukherjee, T. Min, S. C. Kang, J. W. Yun, Trans-anethole ameliorates obesity via induction of browning in white adipocytes and activation of brown adipocytes, Biochimie, 2018, 151, 1-13.

34-A. X. S. Bruker., APEX3 Package, APEX3, SAINT and SADABS, 2016.

35-G. M. Sheldrick, A short history of SHELX, Acta Crystallogr Sect A Found Crystallogr., 2008, 64, 
112-122.

36-G. M. Sheldrick, Crystal structure refinement with SHELXL, Acta Crystallogr Sect C Struct Chem., 2015, 71, 3-8.

37-L. J. Farrugia, WinGX, and ORTEP for Windows: an update, J Appl Crystallogr., 2012, 45, 849-854.

38-C. F. Macrae, I. J. Bruno, J. A. Chisholm, P. R. Edgington, P. McCabe, E. Pidcock,

L. Rodriguez-Monge, R. Taylor, J. V. D. Streek, P. A. Wood, Mercury CSD 2.0--new features for the visualization and investigation of crystal structures, J Appl Crystallogr., 2008, 41, 466-470.

39-E. Graf, Ullmann's Encyclopedia of Industrial Chemistry; Fifth Compl. Revis. Edit. Vol. 's A 3 and A 4 Ed's W. Gerhartz (executive), Y. St. Yamamoto (Senior Ed.), FT Campbell, R. Pfefferkorn und JF Rounsaville. VCH Verlagsges. Weinheim 1985, A 3= 578 S., A 4= 584 S., geb., je Band DM 430,--, Pharm Unserer Zeit., 1987, 16, 63.

40-M. J. Frisch, G. W. Trucks, H. B. Schlegel, G. E. Scuseria, M. A. Robb, J. R. Cheeseman, G. Scalmani, V. Barone, G. A. Petersson, H. Nakatsuji, X. Li, M. Caricato, A. V Marenich, J. Bloino, B. G. Janesko, R. Gomperts, B. Mennucci, H. P. Hratchian, J. V Ortiz, et al., Gaussian v16 $\{\mathrm{R}\}$ evision $\{\mathrm{C}\} .01,2016$.

41-V. Barone, M. Cossi, Quantum calculation of molecular energies and energy gradients in solution by a conductor solvent model, J Phys
Chem A., 1998, 102, 1995-2001.

42-J. S. Murray, K. Sen, Molecular electrostatic potentials: concepts and applications, Elsevier, 1996.

43-R. Idouhli, A. N'Ait Ousidi, Y. Koumya, A. Abouelfida, A. Benyaich, A. Auhmani, M. Y. Ait Itto, Electrochemical studies of monoterpenic thiosemicarbazones as corrosion inhibitor for steel in $1 \mathrm{M} \mathrm{HCl}$, Int J Corros, 2018, 2018.

44- A. Singh, M. Talha, X. Xu, Z. Sun, Y. Lin, Heterocyclic corrosion inhibitors for J55 steel in a sweet corrosive medium, ACS omega., 2017, 2, 8177-8186.

45-R. Idouhli, A. Oukhrib, Y. Koumya, A. Abouelfida, A. Benyaich, A. Benharref, Inhibitory effect of Atlas cedar essential oil on the corrosion of steel in $1 \mathrm{~m} \mathrm{HCl}$, Corros Rev., 2018, 36, 373-384.

46-R. Idouhli, Y. Koumya, M. Khadiri, A. Aityoub, A. Abouelfida, A. Benyaich, Inhibitory effect of Senecio anteuphorbium as green corrosion inhibitor for S300 steel, Int J Ind Chem., 2019, 10, 133-143.

47-M. Sahin, S. Bilgic, H. Yilmaz, The inhibition effects of some cyclic nitrogen compounds on the corrosion of the steel in $\mathrm{NaCl}$ mediums, Appl Surf Sci., 2002, 195, 1-7.

48-M. A. Deyab, E. Guibal, Enhancement of corrosion resistance of the cooling systems in desalination plants by green inhibitor, Sci Rep., 2020, 10, 1-13. 